\title{
LA AFICIÓN AMERICANA DE ALFONSO REYES
}

Una visión definidamente universal caracteriza a la obra ensayística de Alfonso Reyes; sin duda, el mundo en conjunto - como historia, pensamiento, cultura, sociedad- ocupa un primer orden en la actividad reflexiva de este prolífico escritor. Hacedor de múltiples propuestas, de innumerables caminos y de variadísimas proposiciones, sus ensayos revelan la complejidad de su pensamiento y su ilimitada vocación por conocer y abarcar la historia de la cultura. De lo humano, nada le es ajeno. Reyes ensaya muy diferentes vías para perfilar al Hombre. Sus alcances son ilimitados: lo mismo reflexiona sobre la cultura grecolatina, la literatura española de los Siglos de Oro o acerca de las grandes figuras del pensamiento y la literatura de Europa; a final de cuentas, busca siempre una visión universal y aspira sin reposo a estructurar una imagen amplia y total del individuo. De manera más precisa, y sin mengua de otras preocupaciones, América Latina ocupa grandes espacios en su ámbito de reflexión y de crítica, tema que da otros múltiples registros a los ensayos de este intelectual.

En Última Tule ${ }^{1}$, eco de Séneca y de Rodó, Reyes recoge una serie de ensayos que se circunscriben a temas latinoamericanos; texto que muestra cabalmente su afición americana, donde se constata la inclinación y el amor que siente hacia América. Este libro, claro reflejo de su apego y fidelidad al mundo americano, reúne sus más importantes reflexiones sobre el continente; ideas que corresponden muy evidentemente a su pensamiento universalista. América Latina ocupa, desde su perspectiva y dentro de su obra, un importante sitio dentro del conjunto del mundo. La geografía de Reyes destaca, entusiasta y entrañablemente, la región ameri-

${ }^{1}$ Alfonso Reyes, Última Tule, Imprenta Universitaria, México, 1942. Esta obra fue reeditada en $A R O C$, t. 11, pp. 9-153.

NRFH, XXXVII (1989), núm. 2, 371-381 
cana. Sistemático y preciso, Reyes estudia a esta parte del continente, y ofrece un armónico y coherente punto de vista. Sus relaciones con Pedro Henríquez Ureña, Victoria Ocampo, Raimundo Lida, Jorge Luis Borges, Díez-Canedo, Waldo Frank, entre otros, abren los vasos comunicantes para describir y entender a América Latina como una historia de afinidades del conjunto de países que la integran.

Su visión americanista no sólo se documenta cabalmente en libros tan específicos como Última Tule o No hay tal lugar. . . 2, sino que es parte sustancial de toda su labor intelectual; su americanidad está tramada en toda su obra; de manera constante establece comparaciones con diferentes aspectos de la cultura latinoamericana; así por ejemplo, hasta en libros y ensayos sobre el mundo clásico se comprueba su arraigada vocación por este continente:

Sólo un aspecto de Reyes queremos subrayar en esta ocasión: aun en sus obras aparentemente más alejadas del espíritu local, nacional o continental, como podrían considerarse La critica en la edadateniense y La antigua retórica, Reyes acude con frecuencia a recuerdos, ejemplos y citas de autores y obras de su tierra y de nuestra América ${ }^{3}$.

Es decir que sus referencias nacionales y continentales aparecen como una constante; ora como motivo central de reflexión, ora como referencia de contraste o como un sugerente complemento a esa actitud de enriquecimiento o de visión universalista donde lo americano tiene su sitio.

Con la frase "América, cifra de nuestros comunes desvelos", Reyes resume elocuentemente el sentido de su libro Última Tule y su muy definida vocación americanista. América, entonces, se convierte en clave de una de sus más altas preocupaciones intelectuales. En "El presagio de América" que sirve propiamente de introducción a sus trabajos sobre este tema, Reyes amplía la idea anterior y abunda: "Buscando así, a bulto y a tanteos, en el arca de la conciencia, América era la primera realidad que se me ofrecía, el tesoro de mayor peso" 4 . De esta manera, pondera a América como un motivo primordial y fundamental en sus

${ }^{2}$ Con el título No hay tal lugar. . (AROC, t. 11, pp. 335-389), Reyes integra una serie de veinte notas referentes a diversos aspectos de literatura sobre la utopía.

${ }^{3}$ Ernesto Mejía Sánchez, "Nota preliminar", en $A R O C$, t. 13, p. 11.

${ }^{4} A R O C$, t. 11 , p. 11. 
reflexiones, como una zona histórica y cultural que importa conocer y estudiar, en fin, como una región del más alto aprecio y estimación en su escala de los valores.

En sus meditaciones sobre América, Reyes toma como punto de partida la saga del descubrimiento. América, explica, empieza como predicción, presentimiento, conjetura, presagio, invención. América, antes de ser una realidad concreta, es una idea. La imaginación del hombre tuvo necesidad de completar la faz del mundo; así se establece una notable relación entre el perfil geográfico de la tierra y el perfil espiritual del hombre. Uno determina al otro, ambos se complementan y se informan. La búsqueda de la totalidad geográfica implica, de alguna manera, la de la integridad de la conciencia humana. Desde la antigüedad se documenta la idea de completar la imago mundi, existen innumerables y largas referencias que señalan la existencia de tierras ignotas, de atlántidas, de regiones aún no descubiertas que complementarán la figura total del planeta. Antes de la proeza marítima existe, pues, la innegable apetencia de tener una acabada geografía del mundo. Leyendas, anécdotas, Platón, Séneca, la expresión latina Plus Ultra, innumerables mitos dan cuenta de la existencia de desconocidas regiones que precedieron - literaria, poética e imaginativamente- el acontecimiento mismo del descubrimiento. Antes de ser tierra, América fue un sueño: resultado de la imaginación del hombre.

El hallazgo de América es provocado esencialmente por dos vigorosísimas actitudes; por un lado, la elaborada fantasía de tierras imaginarias: el riguroso "presagio" de América: las señales que prevén el suceso, especie de adivinación del futuro, de la corazonada que antecede al descubrimiento; a la par, otra de carácter práctico: el surgimiento y auge de investigaciones geográficas: el hombre que se desvela por conocer el espacio donde habita y que asiste a un notable desarrollo de la geografía (que, como se dijo anteriormente, corresponde a un complejo y rico autodescubrimiento del hombre), ciencia que gradualmente bosqueja la integración de la tierra e informa de los avances, de los caminos y de las rutas que dibujarán el contorno americano. Navegantes, humanistas, comerciantes, gobernantes, la sociedad entera, afirma Reyes, vive afanosamente el presentimiento de América; cada quien, desde su perspectiva, contribuye a completar la faz de la tierra:

Y así, antes de ser esta firme realidad que unas veces nos entusias- 
ma y otras nos desazona, América fue la invención de los poetas, la charada de los geógrafos, la habladuría de los aventureros, la codicia de las empresas y, en suma, un inexplicable apetito y un impulso por trascender los límites ${ }^{5}$.

El desarrollo de la cartografía náutica, la insaciable búsqueda de rutas marítimas, el extraordinario auge de viajes, las determinantes económicas, la exploración de nuevos caminos comerciales, los aportes de Marco Polo a la entonces moderna geografía asiática, la constatación de la esfericidad de la tierra, las antípodas, la navegabilidad de los mares, corresponden a las partes prácticas y científicas que provocan el descubrimiento del continente inédito. El ensayista recoge una sugerente gama de informaciones geográficas y relatos que remiten al pensamiento imaginativo e idealista, notable contribución al gradual conocimiento del mundo. Cabe señalar que estos aspectos prácticos y científicos aparecen generalmente combinados e íntimamente relacionados y determinados por referentes idealistas y fantásticos; por ejemplo la narración platónica acerca de la Atlántida es una marcada influencia sobre los exploradores y cosmógrafos del siglo xV. A los determinantes prácticos se suman los imaginativos: así, se va a proceder a identificar las tierras descubiertas con la imagen de la tan pensada Atlántida.

El continente imaginado es alojado en la tierra firme recién descubierta. Todo aparece como un notable juego de imaginaciones y realidades, donde la imaginación se convierte en realidad, donde no se acaba de determinar los límites del hallazgo. "No sólo la verdad, la misma mentira (como en el Donogoo-Tonka de Jules Romains, equivocación de un sabio que acaba por convertirse en hecho) cuaja de repente en comprobaciones teóricamente inesperadas" 6 . Las reflexiones de este humanista conjuntan generalmente una inseparable suma de aparentes opuestos: verdad y mentira, ciencia y poesía, realidad e imaginación; combinaciones que conducen a la realización del descubrimiento de América. En este mismo sentido, se juega la relación entre los escritores y los navegantes: aquéllos redactaban y éstos cumplían los postulados de la escritura; los navegantes se guían por las instrucciones escritas de los humanistas; la elaboración de cartas y

\footnotetext{
${ }^{5}$ Ibid., pp. 13-14.

${ }^{6}$ Ibid., p. 17.
} 
mapas respondía, de alguna manera, a las influencias e inquietudes humanísticas? ${ }^{7}$.

En su arduo y sugerente repaso sobre su llamado "Presagio de América", Alfonso Reyes se da tiempo para hablar de los protagonistas del descubrimiento. Lugar especial ocupa Colón, a quien trata desde diferentes ángulos: la leyenda, la biografía sucinta, la comedieta, perspectivas que sirven para abonar enormemente la imagen de este individuo y dotarlo de las múltiples referencias que le han sido adjudicadas. "Y así, mientras para unos Colón es el inspirado sin mácula, es el sabio intachable y perseguido, para otros es el truhán osado, que anda de corte en corte estafando con una impostura, o al menos chifladura, que luego resulta una realidad impensada",8.

Precisamente, en un apartado denominado "Comedieta de Colón"', Reyes da rienda suelta a su imaginación y "a modo de juego, podemos forjar, con ayuda de testimonios fehacientes y algo de artificio, uno de los trances del viaje", ejercicio literario resuelto en un diálogo imaginario entre Cristóbal Colón y Martín Alfonso Pinzón, charla que nos conduce a la ficción literaria; con este mismo espíritu creativo redacta una magnífica "Epístola a los Pinzones" donde incluye, de manera sintética, una apología a la manera de ser hispánica, a la índole española:

Milagro de escasa sustentación empírica, de fuertes apoyos ideales: la noción religiosa, la noción monárquica y la noción de la libertad. Obra de colonización deficiente, media España se traslada a América y empieza a vivir según su leal saber y entender. De aquí nuestras repúblicas; de aquí que el orbe hispano desborde con mucho los límites del Estado peninsular. Tal es el sentido profundo de la creación ibérica, creación del pueblo, creación del soldado desconocido que se llama, lisa y llanamente, Juan Español ${ }^{10}$.

Es necesario destacar en la conclusión de esta epístola su carácter anacrónico; es Alfonso Reyes quien redacta una carta a los Pinzones, es una perspectiva desde el siglo $\mathrm{xx}$ hacia el $\mathrm{xv}$, es una reflexión contemporánea sobre una serie de acontecimientos pretéritos, y también un juego temporal donde se considera la proyección de un acontecimiento hacia el futuro. Sin duda, estas pá-

${ }^{7}$ Cf. "El humanismo militante", en $A R O C$, t. 11, pp. 29-30.

8 “'La leyenda de Colón", en $A R O C$, t. 11, p. 31.

9 “'Comedieta de Colón”, en $A R O C$, t. 11, pp. 35-40.

10 "Epístola a los Pinzones", en $A R O C$, t. 11, p. 51. 
ginas específicas sobre la personalidad de Cristóbal Colón, extraordinariamente sugerentes y propositivas, permiten forjar la imagen de un individuo, pero simultáneamente la del espíritu de una época:

Colón posee aquel acometimiento creador de las fuerzas cósmicas. A primera vista, uno de esos italianos cosmopolitas y emprendedores, acaso un tanto quiméricos y arbitristas, sin más riqueza que la inspiración y que se abren paso, no sin rudeza y sin locura, medio poetas y medio brujos, confusos y batalladores, díscolos y osados, descontentadizos, simuladores, tenaces, visionarios, llenos de groserías eficaces, a la vez mezquinos y sublimes ${ }^{11}$.

Esta primera faceta, dedicada exclusivamente a ponderar y a compulsar libros, ideas, autores que se han referido al hallazgo de América, concluye con las ideas que fertilizaron todo su discurso y ensayo sobre este tema: la íntima trabazón de una necesidad poética con una realidad científica, y la de identificación de ideales utópicos en el descubrimiento de las tierras firmes americanas:

Confundido entre las narraciones egipcias, perdido entre las mitologías de la Atlántida, entrevisto por Séneca en su Ultima Tule, vislumbrado en las constelaciones que fulguran en la Divina Comedia, previsto ya por aquellos navegantes portugueses e italianos que eran a un tiempo humanistas y descubridores, el continente americano, antes de ser una región geográfica reconocida, era ya un anhelo apremiante y casi una necesidad poética de las gentes ${ }^{12}$.

Otro postulado de este ensayista mexicano para referirse a América se sustenta en la identificación del continente con la utopía. Ideas imaginativas y fantásticas precedieron al descubrimiento; perfil utópico que cristalizó desmesuradamente con los hallazgos de Colón, que persiste con variantes durante las épocas colonial e independiente y que el propio Reyes retoma como aspecto inherente a Nuestra América:

Se le ha llamado con todos los nombres de la fábula y aun se esperó volver a recobrar aquí el paraíso perdido. Siempre fue algún sitio

11 “La jettatura de Colón”, en $A R O C$, t. 11, p. 46.

12 “En la VII Conferencia Internacional Americana", en $A R O C$, t. 12, pp. $72-73$. 
quimérico y atrayente donde fundar los cimientos de alguna república perfecta. Operada un día la conjunción entre la creadora tenacidad de Italia y el inspirado furor ibérico, América saca la cabeza de las aguas para insuflar los sueños políticos de todos los utopistas europeos ${ }^{13}$.

Desde las páginas iniciales de Última Tule, Reyes hizo innumerables citas y referencias donde se insiste en conceptualizar, de alguna manera, el descubrimiento de América como consecuencia de una larga y minuciosa elaboración utópica, como una relación de causa a efecto, como el tránsito de un "presagio al hecho", el "paso de la quimera a la realidad". Con este principio continúa y hace nuevas proposiciones para la formulación de América como Utopía:

Nuestra América debe vivir como si se preparase siempre a realizar el sueño que su descubrimiento provocó entre los pensadores de Europa: el sueño de la utopía, de la república feliz, que prestaba singular calor a las páginas de Montaigne, cuando se acercaba a contemplar las sorpresas y las maravillas del Nuevo Mundo ${ }^{14}$.

Como gran lector y acucioso conocedor de las utopías clásicas y renacentistas, Reyes subraya el paralelismo entre el descubrimiento del Nuevo Mundo y la instalación de la utopía en América; y hace la caracterización de América como el escenario ideal donde se representarán las mejores y mayores aspiraciones del hombre:

A partir de este instante, el destino de América -cualesquiera sean las contingencias y los errores de la historia - comienza a definirse a los ojos de la humanidad como posible campo donde realizar una justicia más igual, una libertad mejor entendida, una felicidad más completa y mejor repartida entre los hombres, una soñada república, una Utopía ${ }^{15}$.

Así, durante la Colonia, se ensayaron diferentes prácticas de u topías sociales; en la geografia americana fraguó la imaginación europea; en el campo americano se cumplieron las aspiraciones de Europa. En consecuencia, América se convirtió en el espacio

${ }^{13}$ Ibid., p. 73.

14 "Notas sobre la inteligencia americana", en $A R O C$, t. 11, p. 87.

15 "El destino de América", en AROC, t. 11, pp. 57-58. 
idóneo para realizar diversas prácticas de proyectos utópicos: "Pero, entre tanto, el catolicismo ha ensayado también sus utopías sociales en las Fundaciones mexicanas de Vasco de Quiroga, en las primeras misiones del Brasil, en el Imperio jesuítico del $\mathrm{Pa}$ raguay"'16.

El enorme interés de Reyes por las utopías en América lo lleva a desarrollar un ensayo específico: "Utopías americanas"17 donde, además de comentar con especial comedimiento La "Utopia" de Tomás Moro en la Nueva España y otros estudios de Silvio A. Zavala, incluye sugerentísimas reflexiones sobre el tema, explica cómo el descubrimiento provoca una notable "proliferación de sueños políticos en los pensadores de Europa", y de manera específica y particular cómo "Quiroga redibujaba a Moro de acuerdo con la tradición democrática hispana de municipios y consejos"'18. Este mismo tema es ampliamente desarrollado en No hay tal lugar. .. , donde con variantes e ideas complementarias abunda en luminosas reflexiones sobre las utopías americanas.

Reyes enfatiza, es cierto, la idea de la utopía americana como paso previo al descubrimiento y como un modelo posible para los primeros siglos de la América colonizada, pero lo hace sustancialmente también para explicar a la América contemporánea. Influido enormemente por las graves crisis sociales europeas, encuentra en América el espacio ideal, el último reducto para la esperanza del hombre. El optimismo de Reyes responde claramente a una tradición intelectual, la identificación de América con la utopía, y a las apremiantes e inmediatas conflagraciones europeas: "Agradezcámosles en buena hora a los gobiernos americanos que se sientan inspirados en el grande ideal de un Continente que, desde su aparición en la historia, siempre ha anhelado ser el teatro donde se ensaya una humanidad más justa y feliz"'19.

Otra de las ideas fundamentales del pensamiento americanista de Reyes es sobre el sentido de unidad; este ensayista enuncia las bases semejantes, los elementos comunes que hacen de América un conjunto; en apretada síntesis, expone algunas consideraciones que apuntan la homogeneidad del continente:

El análisis del proceso histórico durante el siglo xix y los comienzos del xx nos permitiría todavía establecer cierta paridad de eta-

${ }^{16}$ Ibid., p. 59.

17 "Utopías americanas", en $A R O C$, t. 11, pp. 95-105.

${ }^{18}$ Ibid., p. 101.

19 "Ciencia social y deber social", en $A R O C$, t. 11, p. 106. 
pas que revelan en diverso grado la homogeneidad americana: simultaneidad de los movimientos de emancipación, indecisión inicial idéntica respecto a la forma de gobierno con adopción general de la república, influencia intelectual de orígenes semejantes, marea de las charreteras paralela, otra vez la marea intelectual en la era de los abogados, era económica y técnica mezclada de positivismo y sansimonismo, recientes crisis revolucionarias con derrocamiento de dictaduras, resurreccion de interés para el autoctonismo, etc. ${ }^{20}$

En una visión de conjunto observa que este grupo de países americanos participan de una formación histórica similar, que tienen las mismas bases culturales, religiosas y lingüísticas que les dan una extraordinaria homogeneidad y, en última instancia, determinan su sentido de unidad. Frente al fenómeno de regionalización y diferenciación, exalta más las semejanzas que las diferencias, más las simpatías que los aspectos que pueden separar o fragmentar esa gran extensión geográfica:

Las naciones americanas no son, entre sí, tan extranjeras como las naciones de otros continentes. Tres siglos de elaboración; un siglo de azarosos tanteos, desatados por las independencias y las nuevas organizaciones; medio siglo más de coherencia y cooperación. Tal es, en su perspectiva general, la senda de América ${ }^{21}$.

No cabe duda que la concepción americanista de Reyes se vincula directamente con los ideales bolivarianos; principios relacionados con el sentido de unidad y de integración de los países americanos: y también, por qué no decirlo, con principios utópicos, con aspiraciones de justicia y esperanza: "Fue el refugio de la libertad de conciencia. Fue el semillero de los anhelos republicanos. Fue, es y será el sueño de Bolívar" 22 . Es decir que a América se le asignan innumerables virtudes y posibilidades, se la define como una auténtica tierra de promisión; América como sinónimo de la esperanza humana y como espacio ideal para las "aventuras del bien"'.

Como resultado de sus incisivos y abundantes razonamientos sobre América, Alfonso Reyes establece uno fundamental sobre la "inteligencia americana", a la que define como una forma de

20 "Posición de América", en $A R O C$, t. 11, p. 267.

21 "El destino de América", en $A R O C$, t. 11, p. 62.

22 "En la VII Conferencia Internacional Americana", en $A R O C$, t. 11, p. 22 . 
ser, una manera de actuar, que empieza a delinearse desde la primera generación americana. De nueva cuenta, este ensayista aborda el conjunto americano a través de la inteligencia para explicar la índole americana. En primer término, señala que la participación de América en el conjunto universal se realiza tardíamente; para ello utiliza una metáfora gastronómica, evocación también del Banquete de Platón, que plantea la situación de América:

Llegada tarde al banquete de la civilización europea, América vive saltando etapas, apresurando el paso y corriendo de una forma a otra, sin haber dado tiempo a que madure del todo la forma precedente. A veces el salto es osado y la nueva forma tiene el aire de un alimento retirado del fuego antes de alcanzar su plena cocción ${ }^{23}$.

Esta visión de una historia apresurada, de un ritmó violento, de una serie de experiencias inacabadas, da a la historia de América un sentido muy peculiar. América vive compases y tiempos diferentes a los europeos, "tal es el secreto de nuestra historia, de nuestra política, de nuestra vida, presididas por una consigna de improvisación"'24. Estas circunstancias determinan que la inteligencia americana se vea obligada a una constante función de síntesis y de aplicaciones provisionales. Ese ineludible y necesario trabajo de suma y compendio, explica el escritor, otorga a la índole americana un vigoroso carácter internacionalista.

Reyes afirma que América ofrece la situación ideal para el surgimiento de la "raza cósmica", imaginada por Vasconcelos; pero sobre todo insiste en el aspecto universalista de la inteligencia americana. El hombre americano ha acudido, durante varios siglos, a Europa para obtener sus instrumentos culturales, de cuya circunstancia surge su familiaridad con conceptos y nociones extranjeros. Los ingredientes europeos -y con ellos una implícita universalidad - son un incuestionable elemento de composición social y cultural de la inteligencia americana. El hombre de América habla de Europa como de sí mismo puesto que Europa es parte fundamental de su conformación. Finalmente, sus consideraciones sobre América arriban a la idea de una "mayoría de edad", de un avance, de un grado de madurez y de la necesidad de participar y de formar parte de la estructura del mundo. Se colabora como adultos en la historia de la humanidad.

23 "Notas sobre la inteligencia americana", en $A R O C$, t. 11, p. 83.

24 Ibid. 
La afición americana de Alfonso Reyes, en fin, se identifica plenamente con la utopía, concepto dominante en sus especulaciones americanistas. En este sentido, define a América como tierra de promisión o como el espacio privilegiado donde se cumplirán los grandes principios, ideales y sueños de toda la humanidad. Con claras referencias a innumerables utopías europeas y a pensadores como Simón Bolívar, José Enrique Rodó y José Vasconcelos, entre los más mencionados, Alfonso Reyes construye una de las más sugerentes y optimistas imágenes del continente americano:

Lo hemos visto con una aspiración en los destinos de la sensibilidad y la cultura; aspiración prefigurada ya en la fantasía de los humanistas, los poetas y los navegantes desde antes del Descubrimiento, y proyectada hacia el futuro como una promesa de síntesis mejor, como sueño de una tierra más propicia para la familia de Adán ${ }^{25}$.

Ignacio Díaz Ruiz

Universidad Nacional Autónoma de México

25 "Significado y actualidad de Virgin Spain", en $A R O C$, t. 11, p. 136. 